\title{
Guiding Principles for Delivering Coastal Wetland Carbon Projects
}

Stephen Crooks and Michelle Orr, ESA; Igino Emmer and Moritz von Unger, Silvestrum; Ben Brown, Blue Forests; Daniel Murdiyarso, CIFOR

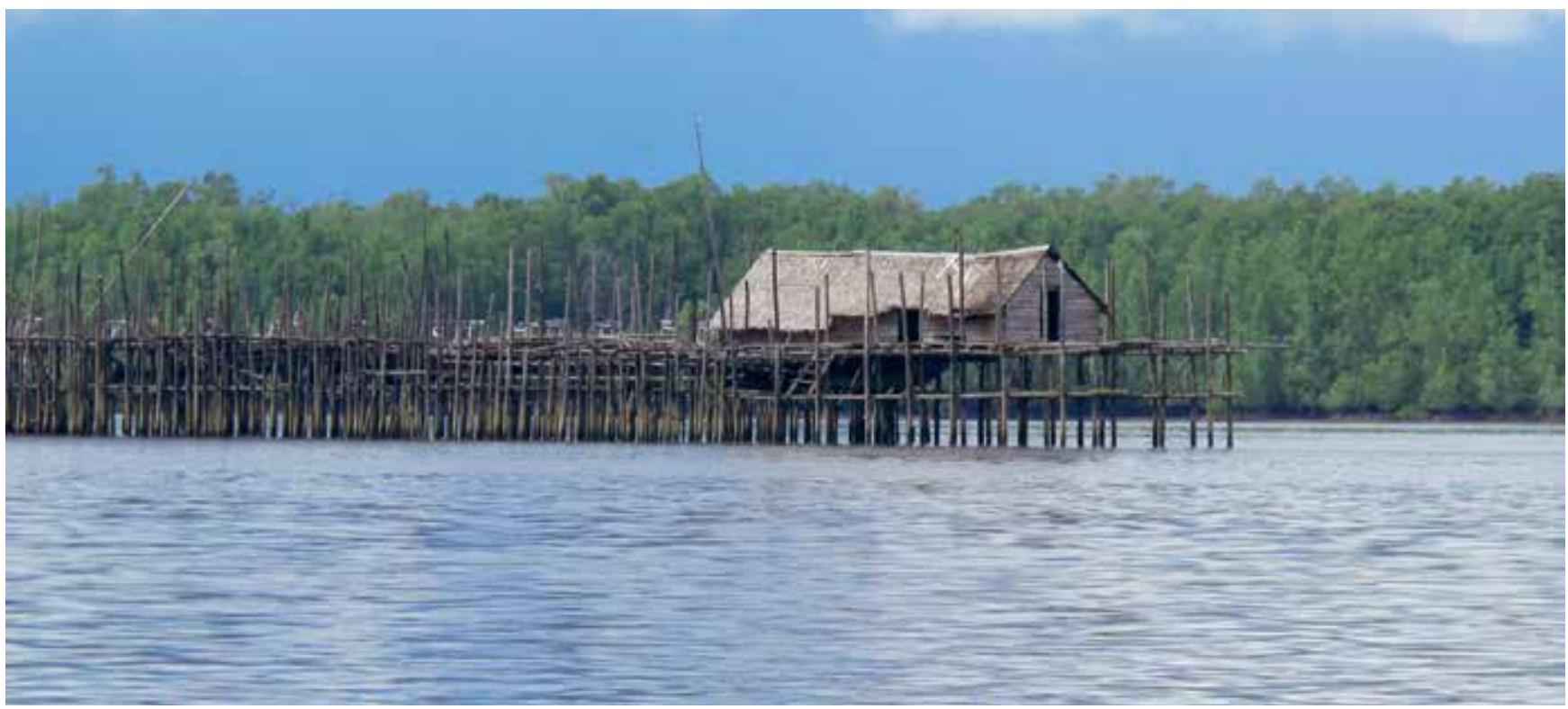

Near shore fishery practice where anchovy - commercially important small shoaling fish - are caught and collected in Karimata Strait, West Kalimantan, Indonesia. Photo by Sigit Sasmito

\section{Introduction}

Coastal wetlands, particularly tidal marshes, seagrass meadows and tidal forests such as mangroves, store and sequester carbon within biomass and soils. Commonly referred to as coastal "blue carbon" ecosystems because of their relevance for the global carbon cycle, these ecosystems provide climate mitigation benefits and a range of other ecosystem services that underpin coastal livelihoods and support adaptation to climate change. These ecosystem services include habitat and food chain support for many species of commercial fish, nutrient recycling, shoreline stabilization, storm protection and flood attenuation.

Over the past 5000 years, a period of rising sea level, coastal wetlands have developed and migrated with sea level changes, accumulating carbon rich soils in many of the world's coastal areas. Over the last century or so, large areas of coastal wetlands have been lost as a result of human activities. Looking forward, remaining coastal wetlands are under threat from human resource use, physical alteration and destruction, altered sediment supplies, nutrient and freshwater supply and pollution. While a broad range of approaches and tools exist for sustainable management of coastal wetlands, estimates indicate that, at current conversion rates, $30-40 \%$ of tidal marshes and seagrasses and nearly $100 \%$ of mangroves could be lost in the next 100 years, with a social cost to humanity estimated to be between USD 6 and 42 billion annually (Pendleton et al. 2012 and the references therein). As coastal wetlands are destroyed, ecosystem services are lost. Wetlands destruction also leads to $\mathrm{CO}_{2}$ emissions from oxidization of organic sediments and biomass, which contributes significantly to global warming.

The importance and value of coastal wetland ecosystem services for climate change mitigation and adaptation provides a basis for development of interventions that conserve and restore these ecosystems. Such interventions may take the form of policy actions, adjusted management actions or project-based investments that lead to improved coastal wetlands conditions. By achieving quantifiable mitigation outcomes, recognizing the value of climate mitigation benefits of wetland carbon management may also generate capital through climate finance mechanisms. 


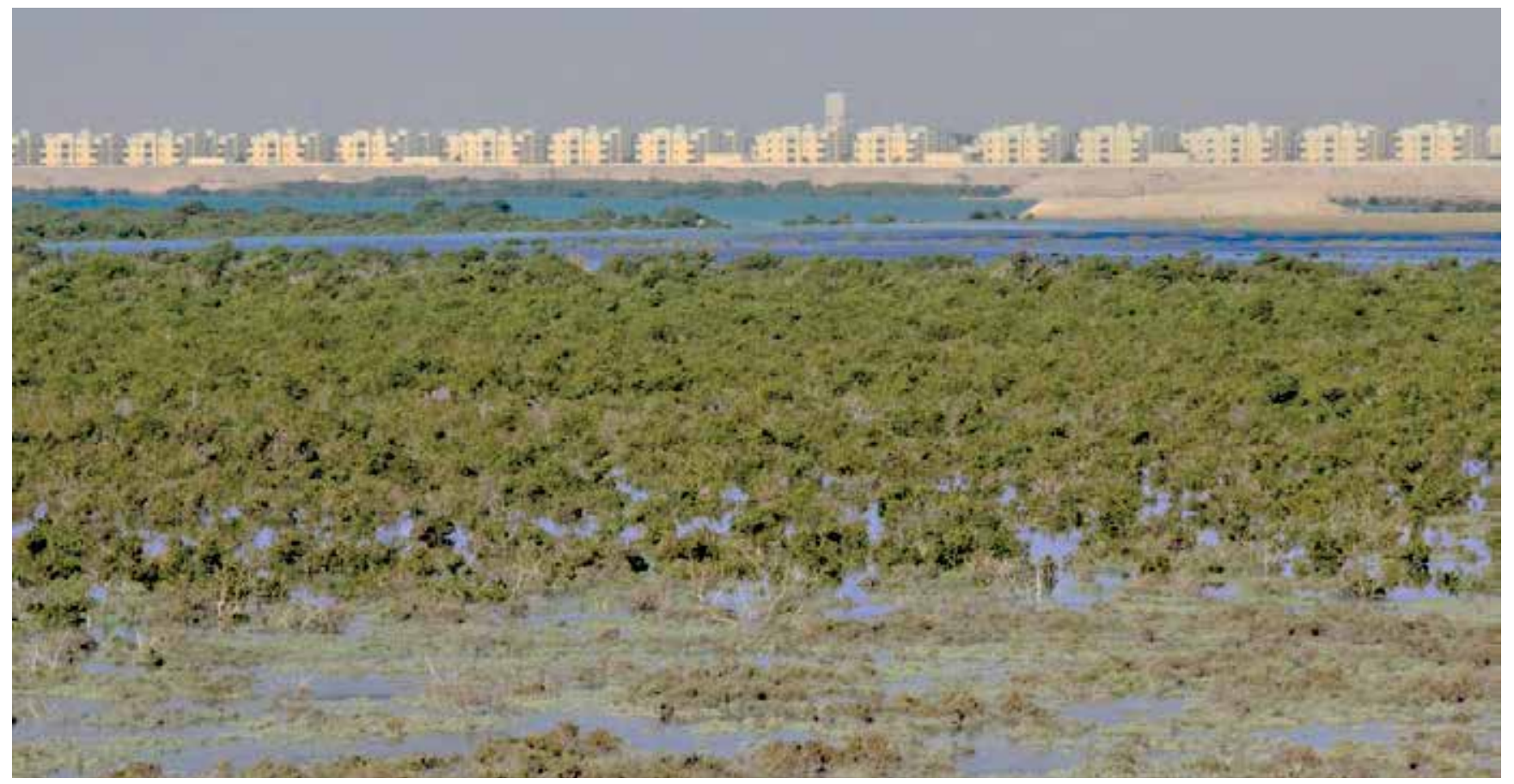

Dwarf mangrove Avicenia marina growing in very saline sea water of the coast of Al Zakhira, Qatar. Photo by Neil Palmer

\section{State of knowledge to support interventions}

1. Climate change mitigation frameworks developed for terrestrial ecosystems can be extended to include coastal wetlands (Climate Focus 2011). Mangroves and temperate tidal forests can be the focus of Reduced Emissions from Deforestation and forest Degradation (REDD+) actions, depending upon national definition of forest. Together with mangroves and temperate tidal forests, tidal marshes and seagrass meadows lend themselves to inclusion under Nationally Appropriate Mitigation Actions (NAMAs).

2. The extension of climate change mitigation frameworks for terrestrial ecosystems to include coastal wetland ecosystems requires that we pay attention to some additional considerations. For example, unlike dryland ecosystems, the soil carbon pool of coastal wetlands is often significant. Coastal wetlands are also part of a continuum of ecosystems from the land to the sea and they respond to a wider range of changes in environmental conditions. They sequester some carbon derived from other ecosystems, e.g. by trapping organic matter. Wetlands found in coastal waters at salinities less than half that of seawater produce methane, which needs to be considered when developing the greenhouse gas (GHG) accounts of an intervention.

3. Sea-level rise will result in an adjustment of the coastal landscape and thus provides a particular challenge in planning blue carbon interventions. In some locations, coastal wetlands will respond resiliently to sea-level rise by keeping pace vertically with sea-level rise or by migrating landward. In other locations wetlands will be lost, especially where landward migration is prevented by human infrastructure or geological features. The drowning of coastal wetlands largely means that ongoing sequestration ceases, and stocks of carbon in aboveground biomass are released while soil carbon stocks in submerged undisturbed soils remain intact. The fate of eroded or disturbed soil carbon remains unclear and depends upon location conditions. The consequences of sea-level rise thus need to be recognized and accounted for when planning and enacting blue carbon interventions.

4. Conservation of existing intact blue carbon ecosystems is technically the simplest and most effective mechanism to manage carbon stocks, and provides the greatest ecosystem benefits. Once a blue carbon ecosystem is destroyed, recovery can be complex due to changes in physical and biological conditions, and presence and need to relocate any infrastructure built across the landscape. Nevertheless, while there are good reasons to prioritize conservation, the benefits of blue carbon ecosystem recovery remain high (and the second best option) especially where restoration can be carried out at landscape scale.

\section{Lessons from previous projects}

1. There are only limited examples of blue carbon ecosystem restoration interventions that account fully for GHG and access carbon markets for finance. Such planning experience exists but has yet to be widely enacted.

2. While blue carbon is a new concept, planning successful conservation and restoration of coastal ecosystems is an established practice with a learning curve of experience spanning over 40 years. Experience has developed at different rates and with different foci around the world but each brings lessons that can be shared as examples of common good practice. This learning encompasses phases of increasing complexity: (1) building wetland conservation and restoration experience and capacity; (2) scaling up to establish multi-use functional landscapes integrating 


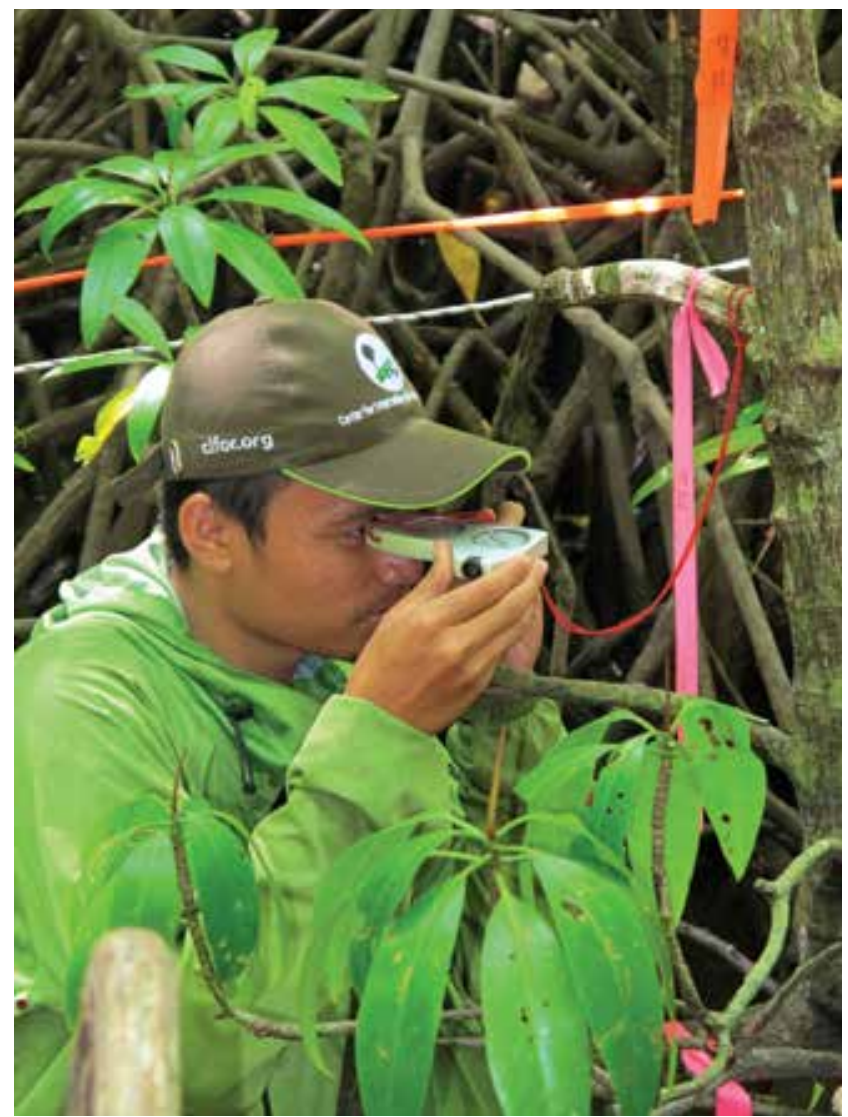

Determining the right direction using compass in a dense mangrove stand. Photo by Kate Evans

community activities in balance with sustaining environmental conditions; and (3) inclusion of climate change adaptation and mitigation in land-use planning.

3. The technical ability to successfully restore coastal wetland ecosystems today is available on a global level, even if it is not always applied. Recent years have seen increasing interventions to integrate ecosystems within functioning landscapes - ranging from large-scale restoration programs (each tens of thousands of hectares) to village-level integration of mangrove restoration with aquaculture. The challenge is to expand the use of good practice to reduce the rate of project failure, and to include adaptation strategies to sea-level rise and other climate change impacts.

4. To achieve a successful intervention, coastal wetland conservation or restoration should be planned with a landscape response to climate change in mind. Connecting climate change mitigation with adaptation planning will greatly increase the likelihood that blue carbon interventions will be successful.

5. Geomorphic and engineering tools exist to aid in the understanding of how blue carbon ecosystems will respond to sea-level rise, thus supporting project planning and design.

6. Project success is greatly increased if local community engagement and capacity building predates or accompanies the intervention. Examples of good practice exist.

\section{Considerations for developing blue carbon interventions}

- Blue carbon policy and management interventions can be deployed in all coastal settings to improve reductions in GHG emissions and removals. However, not all coastal settings will be attractive from a carbon finance perspective because of the cost or complexity of projects and may be more suited to other policy approaches. Potentially, public-private initiatives or stacking credits for multiple ecosystem services may increase project take-up.

- In preparation for higher rates of sea-level rise there should be consideration of site prioritization, focusing on areas most resilient to sea-level rise.

- There are no structured templates for enacting blue carbon interventions. General planning frameworks have been developed for carbon projects and for wetlands restoration projects. Good practice can be drawn from both of these frameworks. The following steps, modified from Olander et al. 2011, are appropriate for blue carbon intervention planning:

- define the project concept and perform a preliminary feasibility assessment;

- define a target market or standard;

- establish effective community engagement;

- design the project activities early on;

- assess non-permanence risk and develop mitigation strategies;

- secure project development finance and structure agreements;

_ provide for legal due diligence and assess carbon rights;

- provide for a social and environmental impacts assessment and provide a roadmap showing how environmental and social standards can be met;

- maintain ongoing liaison with regulators;

- define management roles and responsibilities for project implementation.

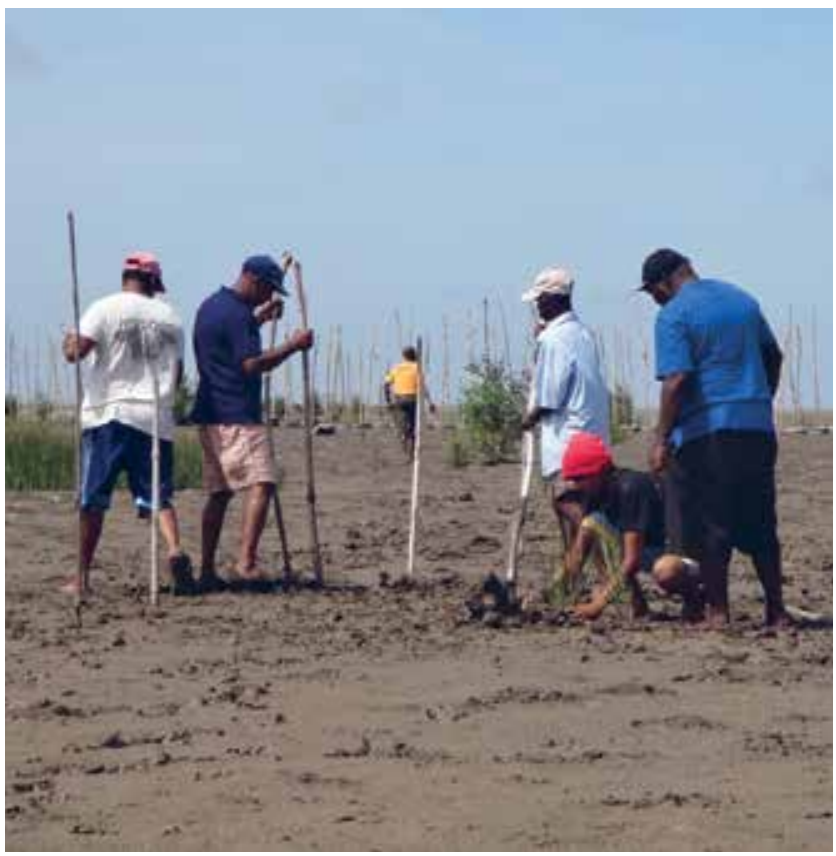

Mangrove planting in Guyana. Photo by Steven Crooks 
- An early stage feasibility assessment is strongly recommended to set an intervention on the right path, while recognizing technical, legal, financial planning and community engagement considerations.

- An array of carbon accounting methodologies exists for AFOLU projects that include both biomass and soil organic carbon pools and sources of GHG emissions. Extension of a REDD+ modular methodology including tidal wetlands restoration and conservation is under development. Recognizing the additional requirements for coastal wetland carbon projects, new procedures are proposed under the draft Verified Carbon Standard methodology for Tidal Wetland and Seagrass Restoration. These procedures include: (1) guidance on defining project boundaries in settings subject to mobility with sea-level rise; (2) approaches for developing baseline and project scenarios; and (3) procedures for quantifying autochthonous (derived from sequestration on-site) and allochthonous (derived from another ecosystem) soil carbon constituents and methane emissions.
- A particular uncertainty that has not yet been resolved is the fate of carbon that erodes from a tidal marsh with a sea-level rise. For projects involving carbon crediting it is conservative to assume no redistributed carbon is oxidized in the baseline and all redistributed carbon is oxidized in the project case. While further research is required on this topic, in a welldesigned conservation or restoration project, the resilience of existing wetlands to a sea-level rise is likely to increase.

\section{References}

Climate Focus 2011. Blue carbon policy options assessment. Report to the Linden Trust for Conservation, Version 4.0, 15 June 2011. Climate Focus, Washington, DC. Accessed 27 November 2011. http://www.climatefocus.com/documents/ files/blue_carbon_.pdf

Olander J and Ebeling J 2011. Building Forest Carbon Projects: Step.by.Step Overview and Guide. In Ebeling J and Olander J (eds.). Building Forest carbon Projects, Washington, DC: Forest Trends. Accessed 27 November 2014 http://www. forest-trends.org/documents/files/doc_2555.pdf

This brief is summarized from UNEP and CIFOR 2014. Guiding principles for delivering coastal wetland carbon projects. United Nations Environment Programme, Nairobi, Kenya and Center for International Forestry Research, Bogor, Indonesia, 57pp.

This guidance document distils best practice principles for coastal wetland carbon projects, drawing on a long history of project development and implementation in fields of wetlands restoration, terrestrial carbon projects, carbon policy and community engagement. It is targeted at people familiar with carbon project and policy development or wetlands restoration who are seeking an overview of the additional requirements necessary for successful coastal wetland or blue carbon interventions.

This work was carried by the United Nations Environment Programme (UNEP) and the Center for International Forestry Research (CIFOR), in collaboration with IOC of UNESCO, Ramsar Convention and IUCN. It was supported by the Government of Sweden through UNEP and the US Agency for International Development (USAID) through the Sustainable Wetlands Adaptation and Mitigation Program (SWAMP), a collaborative effort by CIFOR, the USDA Forest Service (USFS) and Oregon State University.
Produced as part of

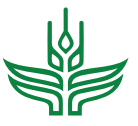

CGIAR
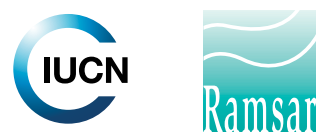
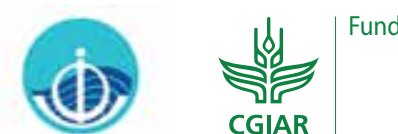